\title{
Perspectives from Mothers on Child Maintenance and Family Well Being: Policy Implications
}

\author{
Paulette Andrea Henry \\ Department of Sociology, University of Guyana \\ 95 Amsville Housing Scheme, New Amsterdam, Berbice, Guyana \\ Tel: 592-650-7855/333-2097 E-mail: phenryugbc@ yahoo.com
}

Received: February 29, 2016 Accepted: March 13, $2016 \quad$ Published: June 11, 2016

doi: 10.5296/iss.v4i1.9122 URL: http://dx.doi.org/10.5296/iss.v4i1.9122

\begin{abstract}
Very often mothers are left to bear the social, emotional and financial burdens of parenting when relationships between parents do not work out. Although fathers claim to yearn for better relationships with their children, poor relations with mothers of their children is often cited as the primary reason for their estranged relationships with their children. Building upon an initial research undertaken to ascertain the impact of child support, father child relationships and family well being, this article will present the findings from a survey undertaken with mothers to garner perspectives on child maintenance and family well-being. It will seek to suggest mechanisms which can influence policy for child maintenance and parent child relations when parents are separated with the intent towards the improvement of child and family wellbeing.
\end{abstract}

Keywords: child maintenance, mothers, parent relationships, child and family well-being, policy 


\section{Introduction}

A child's well being is positively affected when both parents are engaged in a good relationship even though they may not be sharing a union. In addition, both the child and family well being are affected when their economic stress are reduced and there is not the additional worry about finances. This article aims to bring attention to child maintenance and family well being from the perspectives of mothers. It will also seek to define the gender and policy implications pertinent to child maintenance. According to the Guyana Custody, Contact, Guardianship and Maintenance Act 2011, persons who have parental rights have a duty to maintain their children i.e. they have a duty to provide financial support for the welfare of their children. It therefore means that whatever support is given must be sufficient to meet the needs of the child. Whilst this policy is gender neutral, in the context of Guyana, women are the persons who are primarily affected since children within this context are usually left with their mothers or mother figures.

\subsection{Primary Objective}

Building upon the research completed earlier with fathers to ascertain their perceptions on father child relationship and child maintenance (Henry, 2015), the key objectives of this research are to ascertain mothers' perception on child maintenance and the court system, parental relationships and family wellbeing as well as policy implications. Thus the critical questions that will inform this study are:

1. What are the strengths and weaknesses of the child maintenance system and its impact on mothers?

2. How do parental relationships affect child support?

3. How does non-payment of child support affect child and family well being?

4. What improvements do the child maintenance infrastructure need for efficiency in child maintenance payments?

5. What are the policy implications when fathers do not nor cannot pay?

\section{Scope}

This research presents perspectives of mothers on child maintenance and child and family wellbeing. It is anticipated that combined data from both mothers and fathers can be instructive to policy makers working on child rights and child protection.

Whilst Henry (2015) asserts that agencies working with men must understand how the family within which the child is located becomes even poorer due to lack of the father's economic and psychosocial support, the writer also suggests that where women are unable to secure child maintenance from fathers either due to their inability to pay or failure to locate them, interim social security measures should be provided for child support until the father is able to meet these financial obligations, thereby reducing the burden of child care on women and strengthening the emotional and financial well being of the child and family. 


\section{What the Literature Says?}

\subsection{Child Maintenance, the Court: Impact on Mothers}

Much of the literature that exists examines the role of fathers as it relates to child maintenance with the emphasis on the economic role of the father with very little documenting mothers' responsibilities for child maintenance. Traditionally, the legislation has been silent on the role of mothers and largely encapsulated the stereotypical roles of fathers as the primary providers of their children. Women were largely perceived as the primary nurturers and caregivers. Examining family structures in the Caribbean, Seegobin (2003) stated that the African-Caribbean family has unique mating and childrearing patterns. Some of these patterns include absent fathers, grandmother-dominated households, frequently terminated common-law unions, and child-shifting, where children are sent to live with relatives because the parents have migrated or have begun a union with another spouse. Families tend to have a matrifocal or matricentric structure. Seegobin cited the work of Sharpe (1996) who noted that, "To say that African Caribbean fathers and other men are fundamental to the socialization of children and to an understanding of African Caribbean family life is putting it mildly. That Caribbean men care for their family and provide for them economically has been demonstrated. However, their emotional a vailability and their social ties to children are unclear" (Sharpe 1996, p. 261-262). In contrast, Seegobin, (1999) asserts that more value is ascribed to the East Indian male who within his family structure is the final authority in most matters with the mother's principal role being to take care of the children and be the primary nurturer in the family and the home. 'In her discourse with males on the issue of child maintenance, Henry (2015) found that fathers, regardless of ethnicity, expressed the desire to spend time with their children and having a meaningful role in their lives of their children but were concerned that the quality of the relationships with the child-mothers may impact negatively on their children, hence they preferred to wait until the children "grew up".

Maintenance, according to the Guyana Custody, Contact, Guardianship and Maintenance Act (2011), refers to persons with parental rights having a duty to maintain their children i.e. they have a duty to provide maintenance or money for the welfare of their child(ren). This Act is gender neutral and clearly stipulates that all parents, whether married or not, have a duty to maintain their children. They have this duty even when their children are not living with them. It therefore means that whatever support is given must be sufficient to meet the needs of the child. However, despite this modern piece of legislation, the burden of parental care still rests with primarily with women either as mothers or grandmothers who often end up undertaking the caregiving and nurturing role when a relationship ends. In Guyana, the Protection of Children Act (2009) states that the best interest principle should always be employed when decisions regarding a child's safety, health and well-being are being made. Examples are seen in the Adoption of Children Act of 2009 which provides for the child's voice to be heard. The Status of Children Act of 2009 bestows equal rights on all children irrespective of how they were conceived. The Custody, Access, Guardianship and Maintenance Act (2011) ensures the best interest of the child is the primary consideration in related court decisions. Children over twelve years of age are to be allowed to express their opinions or views regarding their care and custody, unless they are unable to do so. The opinions and views of children under twelve years 
old shall be heard and considered in coming to any decisions once the child is sufficiently mature and can understand the proceedings

Due to both their single parent status and financial status, many women are often forced to use the Court to garner financial support to address child wellbeing. Dissatisfaction has been expressed within the print media as women contended that the system is not helpful and they are forced to wait for prolonged periods to get their monies at the Court, borrow money and in some cases even return the next day to complete their transactions which poses an additional burden on their limited resources (Henry,2015). Evidently, despite the updated legislations, there still appears to be some discrepancies with its utility by the Guyana Court up till 2014, as court records point to inconsistencies in record management pertinent to current legislations which may result in the delayed payment processes.

\subsection{Child Wellbeing}

As alluded to earlier, there is very little indigenous literature in Guyana and the Caribbean that address mothers, the judicial system and how this system impacts mothers within the context of childcare and child well-being. Much of the data accrued pertinent to recent studies emanated from media reports. Henry (2015) uses the definition of NEF (2009), which states that well being is described as a dynamic process in which a child's external circumstances, socioeconomic background, physical surroundings are constantly interacting with their individual characteristics to satisfy their needs and thus build psychological resources, capabilities and positive interactions with those around them. Other writers similarly addressed this phenomenon noting that the quality of relationships and children's personal well being component is often missing from discourses on child well being. (Bradshaw et al, 2006, Bartfeld et al 2000). In sum, compared to children in two-parent families, children in single-mother families are more likely to experience economic hardship, to have lower educational achievement, and to have more behavioral problems (Amato, 2005; Krein \& Beller, 1988) It is important to note, that whilst economic resources is positioned as being of central importance to factors impacting child well-being, other areas of critical importance include social, emotional and cultural and must be considered. (PWG 2003:3)

Relationships are an important component of child well being. In seeking child support, men may not understand that women are required to identify them as a condition of receiving welfare. Or they may blame mothers for applying for welfare and creating the obligation in the first place. Mothers, in turn, may attribute the necessity for welfare to the failure of fathers to support their children. Failure to understand the pass through system may also create mutual suspicion about where the money is spent. Finally, the economic demands put on poor fathers by child support, particularly if large arrearages develop, further strain often shaky relationships. (Waller and Plotnick, 2000)

\subsection{Policy Implications}

Child support policy seeks to ensure that parents who live apart from their children contribute to their financial well-being. This objective according to Wallner and Plotnick (2001) serves several important public policy goals by reducing poverty and financial insecurity among 
children and their custodial parents; preventing single-parent families from entering the welfare system; helping families on welfare leave more quickly by substituting private, parental income for public welfare; and reducing public spending for welfare. Child support policy also seeks to affirm the widely held belief that parents are morally and socially obligated to support their children. Henry (2015) asserts that a child's economic circumstance is critical to the child's well being and there is an extremely close correlation between child maintenance and child and family economic situation, so that when a father does not pay his child's support, the predominantly female headed family sinks deeper into the mire of poverty thereby affecting child and family well being. There is also the need in Guyana for a holistic policy on child support/child maintenance. However, child maintenance must not be considered in such a manner that payment is the only factor for child well being. Building a supportive framework for the child to have good relations with both parents, where it is practical, must be considered in the best interest of the child.

Whilst it is unclear how effective enforcement policies are in Guyana, enforcement is extremely important in any policy on child maintenance. In the US, the articles on mothers and children show that enforcement policies are quite successful in improving the circumstances of those families that receive child maintenance. The policies have increased the numbers of fathers who pay something and the size and reliability of those payments, in particular for never-married women. Even though the primary income source for single mothers is (and always has been) their earnings, child support payments of a few hundred dollars can make a real difference in children's standard of living when those earnings are low (Waller and Plotnick, 2000). Enforcement in Guyana however, can become a burden on women, who when fathers do not pay must seek a warrant for his arrest and then cooperate with law enforcement officers in his identification. This system was very similar to what Waller and Plotnick (2000) also described in the US.

\section{Methodological Approach}

This research utilizes a mixed method approach to gather data. Document studies which included newspaper reports and other writings were analyzed. Focus interviews were conducted with thirty (30) mothers to seek their perceptions on child maintenance and its impact on their relationship with their child. Mothers were randomly selected over a week as they went to uplift their child support payments at the magistrate courts. Respondents were drawn from both rural and urban magistrate courts. The responses were analyzed and informed the findings.

\section{Interview Protocol}

Each interview lasted approximately thirty minutes. All participants were informed about the reason for the research and confidentiality procedures and agreed to conduct the interviews. Participants were thanked for sharing their information. 


\section{Macrothink}

\section{The Findings and Discussions}

\subsection{Demographic Data}

The thirty (30) participants were mothers who were all in receipt of child support via the Court, and volunteered to participate in the study. Their ages ranged from 20 to 45 years with the large majority (17 or 56 percent) being between ages $25-35,8$ or 27 percent being between ages 36 to 45 and the minority group 5 or 17 percent being the youngest mothers. The inference drawn here is that older mothers may have ceased receiving child support since their children would have become older and hence there was no longer a need or would have aged out of the system, whilst those within the 25-35 age group are at the stage where children are young and finances may be scarce especially where mothers do not work.

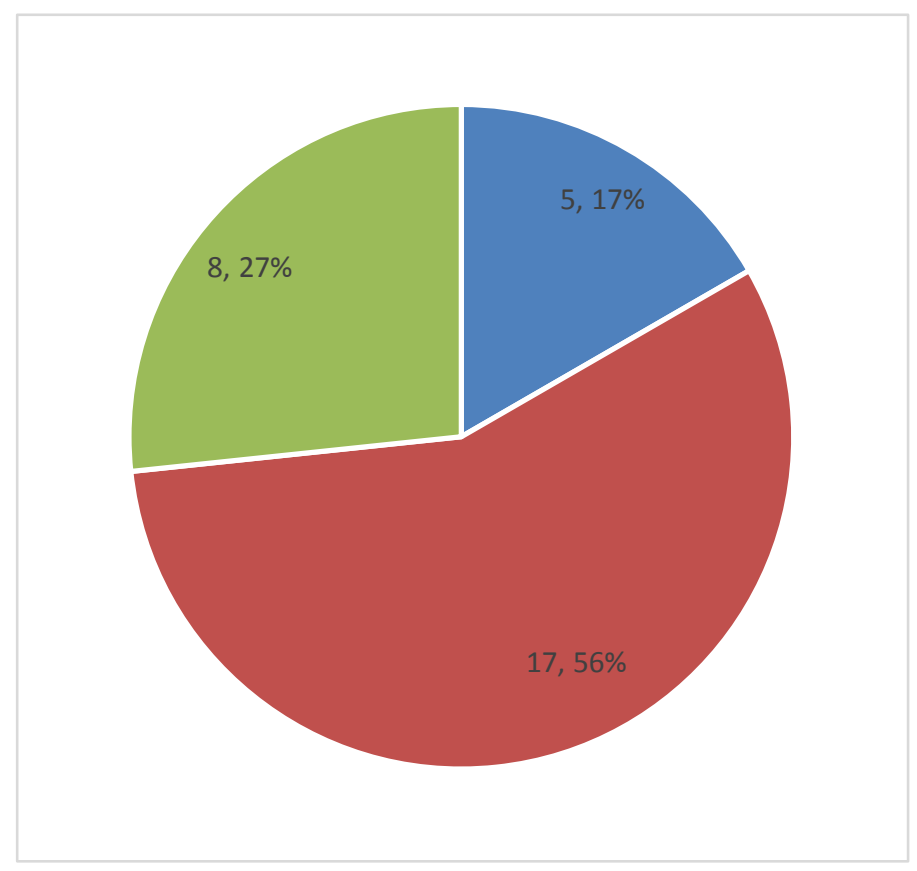

Figure 1. Age range of respondents receiving child maintenance via magistrate courts

Employment was an important consideration since it also served as an indicator of need for the financial support. Just over half of the respondents were employed, 16 or 53 percent, with the others who comprise a significant minority, almost half of the population (14 or 47 percent) being unemployed. Child- mother employment is an important variable which must be considered, since unemployed mothers are more likely to have an urgent need for the timely receipt of child support. The supporting structures of the court where payments are received must be made responsive of the need to expedite this process with improved efficiency and at minimal costs to mothers. Additionally, when examined by ethnicity, the data show that 17 or 56 percent of the mothers were of African ancestry and the remainder (13 or 44) percent were East Indians. The data seems to be consistent with earlier findings 
which indicate a strong female dominance in homes of persons of African ancestry in contrast to that of the East Indian male and would seem to suggest that East Indian males may be more present, hence reducing the need for child maintenance via the courts or that the family structure could be better positioned to support mothers when fathers financial support is absent.

\section{Marital Status of the Respondents}

An assessment of child and family well being must consider the stability of the relationship within which the child is located. It is usually anticipated that if a child lives within a stable union, that child will be mentally and psychologically capable of coping with the everyday hurdles of life since the child is more likely to benefit from social and financial security associated with stable families. The majority of the respondents, 18 or 60 percent, were not married with 3 or 10 percent engaged in a visiting relationship and only a small proportion of the respondents indicating that they were either married (4 or 13.3 percent) or living home 5 or 16.7 percent). When contrasted with those who were not married or engaged in a visiting relationship, concerns may be expressed about the psychosocial wellbeing of the child since children in stable environments tended to fare better. In addition, where mothers were not in stable relationships and unemployed, this may also add to the psychosocial distress which the children may experience when their home do not receive adequate finances in a timely manner.

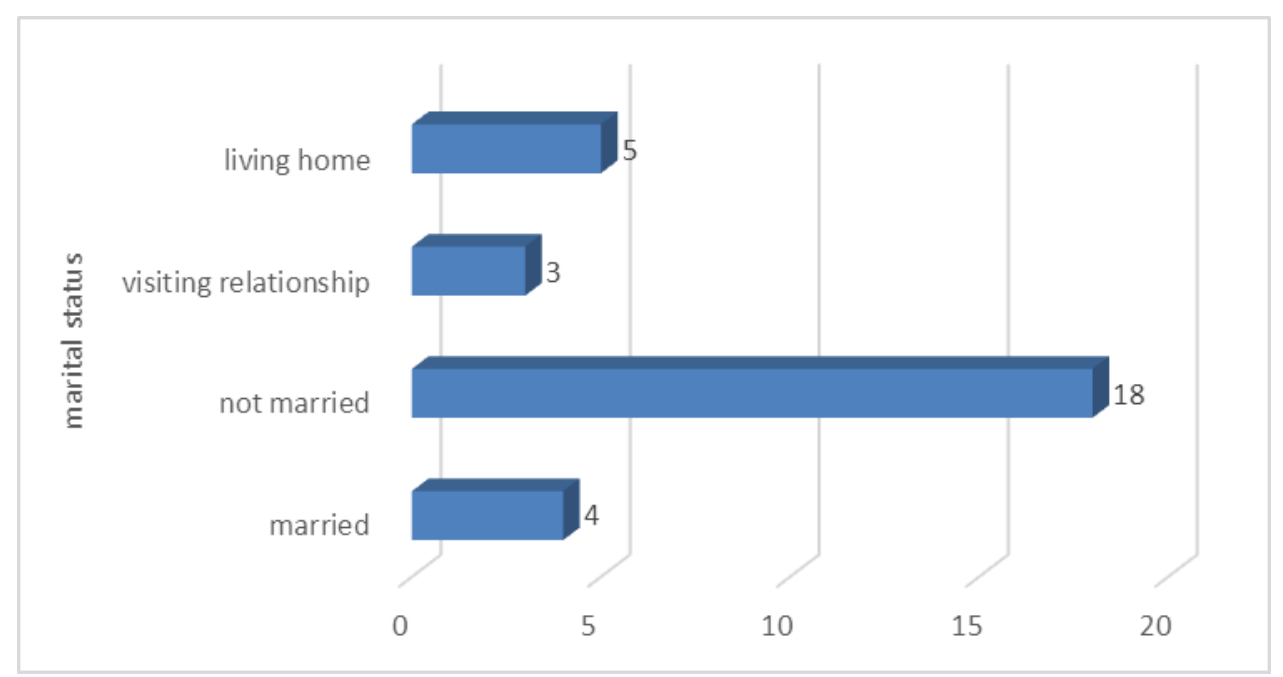

Figure 2. Marital status of recipients

\subsection{Mothers, the Court System and Payments}

Henry (2015) points to the punitive nature of the court system where child maintenance payments are uplifted. It was found that mothers, due to their differential circumstances, are negatively impacted when fathers do not pay or when the system is unduly burdensome and mothers bear the costs of having to return on more than one occasion to uplift payments. 


\section{Macrothink}

Even getting the court system to work efficiently in issuing summons on recalcitrant fathers who do not pay was cited.

Further, the data show that the majority of the respondents (50 percent) have been receiving child support between 1-3 years with 17 percent receiving support for more than five years. What was evident from both observations and the data, is that more of the younger mothers made up the majority of the persons (73.3) seeking support, all being under age 35, suggesting that older mothers were not there since their children may have aged out of the system.

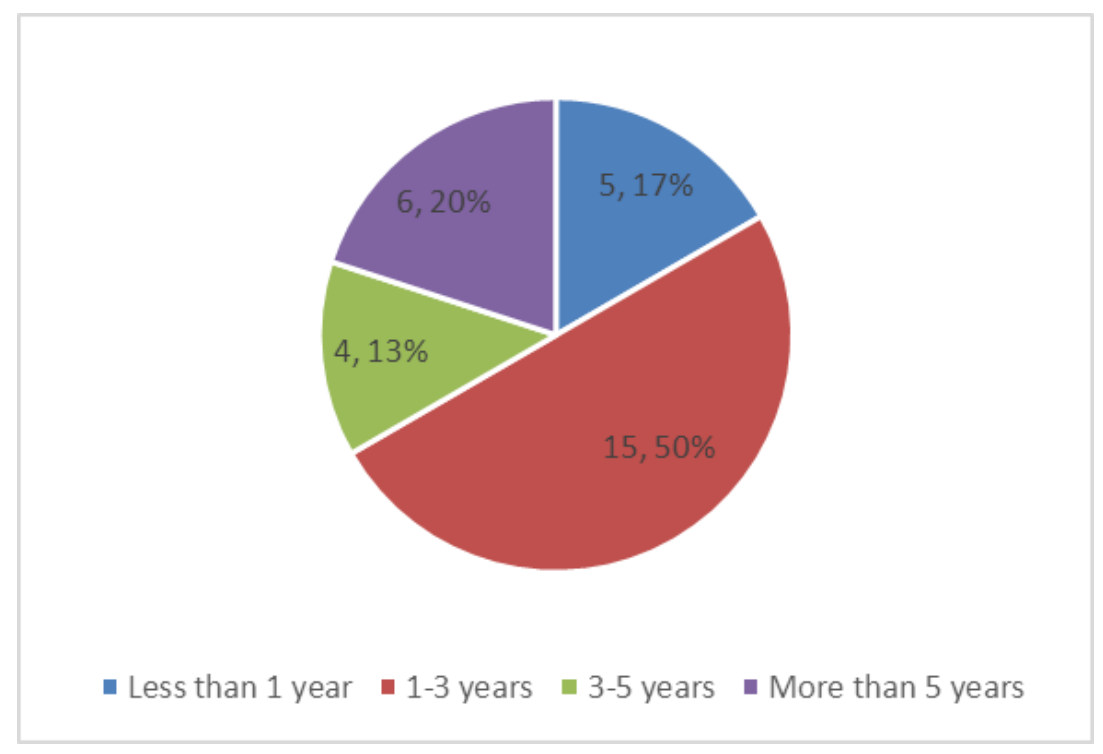

Figure 3. No of years receiving child support

Further, evidence show that the large majority of fathers do not pay their child support payments on time. Based on the findings, only one person paid consistently on time with 12 or 40 percent meeting their payment date sometimes, whilst more than half of the respondents, 17 or 56 percent rarely or never met their payments on time. Obviously this impacts the family and household within which the child is located, especially those where mothers do not work or are in non-marital relationships and are dependent on the support from fathers. 


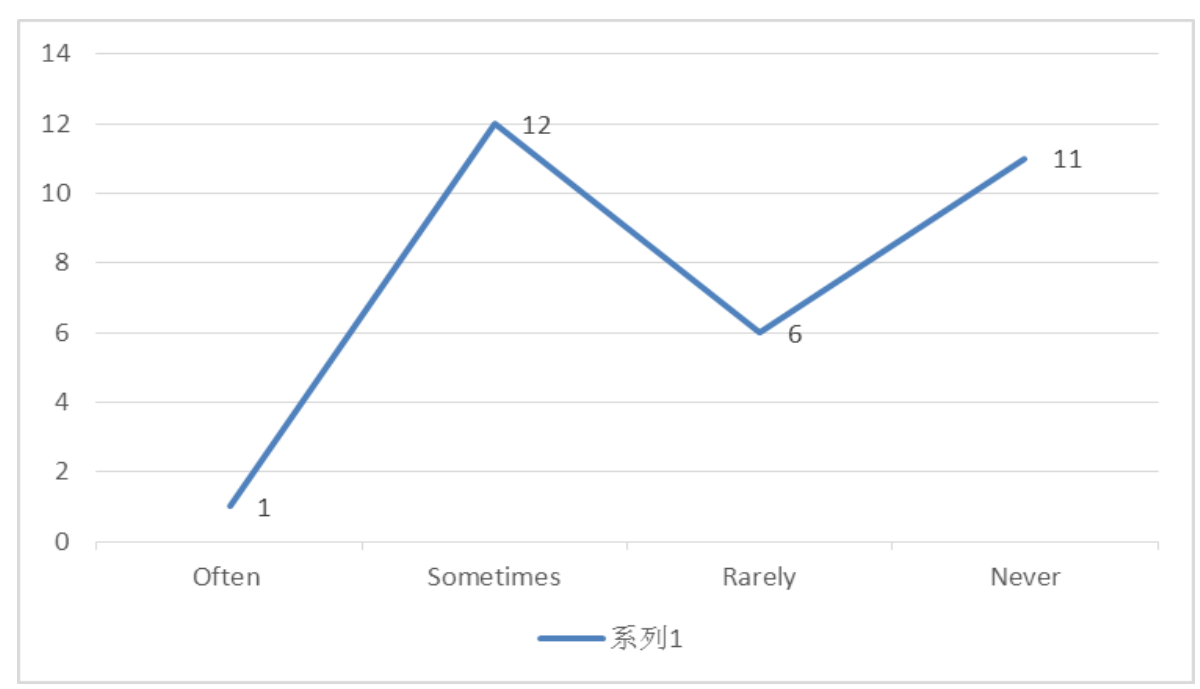

Figure 4. Timeliness of Child support payment by fathers

\subsection{Father- Child Relationship}

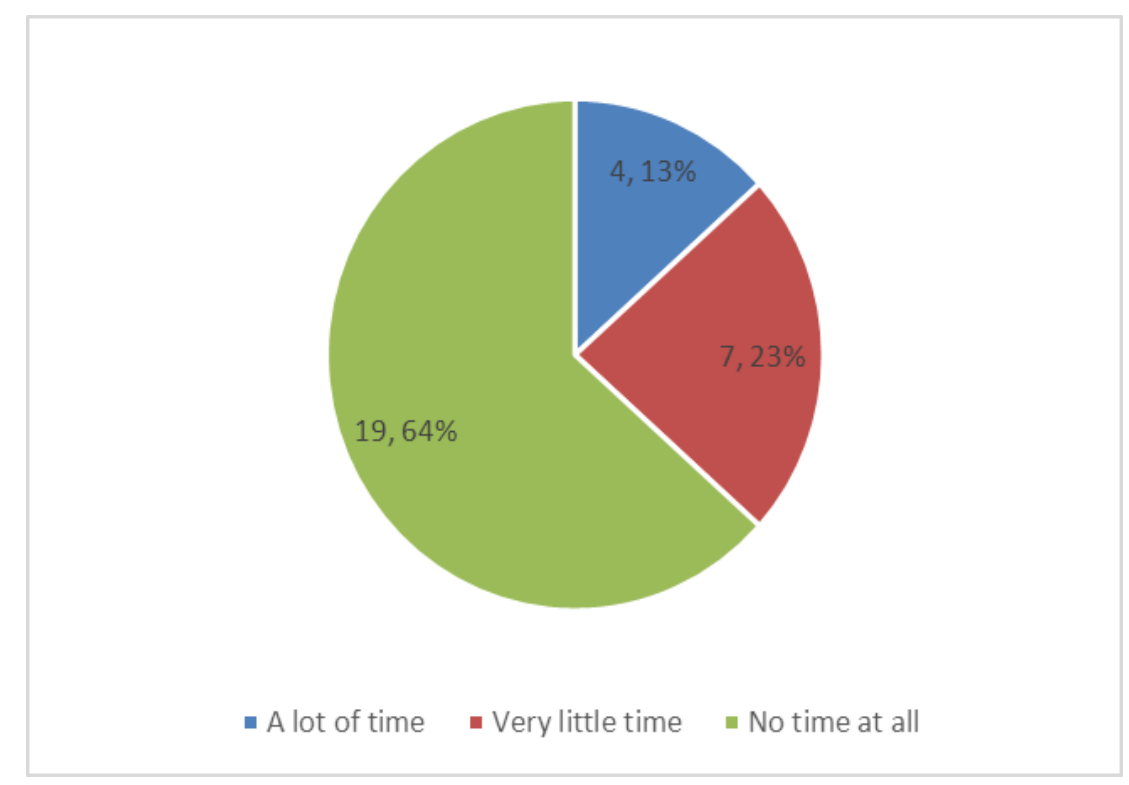

Figure 5. Time father spent with child

The importance of father child relationship has been discussed as an important element in child and family well being. This study asked a series of questions to ascertain the nature of father child relationships when child maintenance or child support is an issue of concern. Questions pertinent to time spent with child and reasons for time spent were sought along with descriptions on the quality of the mother-father(parent) relationships. These were all 
designed to provide an understanding of how these factors may contribute to the overall child and family relationship.

When asked how much time does the father of the child(ren) get to spend with the children, the responses were not very favourable (See Figure 5). At least 2 of every 3 respondents interviewed (64 percent) indicated that the fathers spent no time with the children whilst only 4 or just over 1 out of every 7 indicated that the fathers spent a lot of time with their child(ren). The litany of responses offered by mothers on why fathers do not spend time with their children are outlined in Table 1 . The primary reason being that he(father) either chose not to, followed by work commitment. Relationships with their significant others are critical to whether fathers were able to spend time with their children. As explained by Hart (2004:24), children are fundamentally social beings, for whose mental and emotional health it is vital to enjoy positive connections with others: a sense of consistency, continuity and reciprocity in relationships. Conflict may threaten children's well-being since it commonly shatters social networks in a variety of direct and indirect ways - through death, displacement, the loss of trust, and so on.

Additionally, mothers' perception on why fathers do not spend enough time with their children were sought and their views ranged along the spectrum of personal choice, work, or new relationships. (See Table 1) Even though a few mothers would have identified that would

Table 1. Mothers Perception on why fathers do not spend adequate time with children

\begin{tabular}{lcc}
\hline Reasons offered & No & Percent \\
\hline He choose not to & 9 & 30 \\
His new family & 2 & 6.7 \\
work commitment & 6 & 20 \\
Always busy & 4 & 13.3 \\
Don't know & 4 & 13.3 \\
The new woman & 3 & 10 \\
His Priorities & 2 & 6.7 \\
\hline
\end{tabular}

On the other hand, the study sought to get from mothers' whether they wanted their children to spend time with their fathers. The findings suggest that quite a number of the mothers $(20$ or 66.7 percent) indicated that they wished that their children could spend more time with their father whilst 10 or 33.3 percent said that they did not want their child to spend more time with their father or offered no response. The respondents were also asked if they felt that their children missed or wanted to be with their fathers. The responses showed that a good majority of mothers ( 20 or 67.7 percent) stated that their children missed/wanted to be with their father whilst a smaller number of respondents ( 6 or 20 percent) of them did not feel that their child missed or wanted to be with their father and 4 or 13.3 offered no response. 


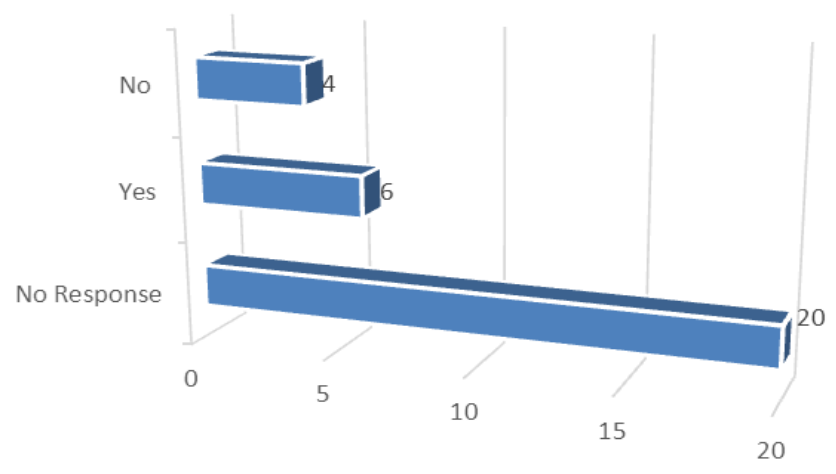

Figure 6. Mothers' perception on whether fathers missed their children

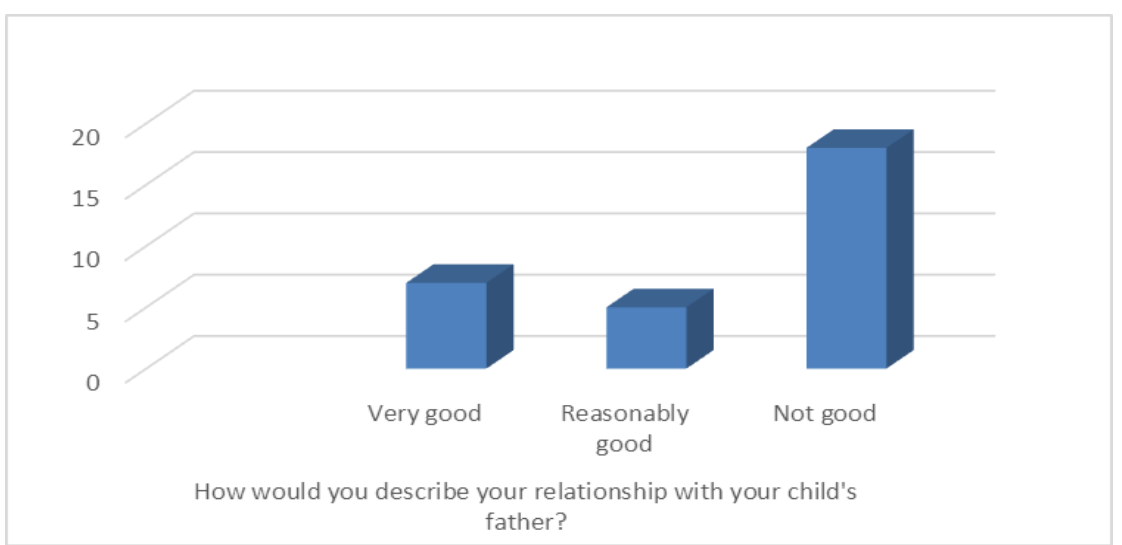

Figure 7. Mothers' relationships with child's father

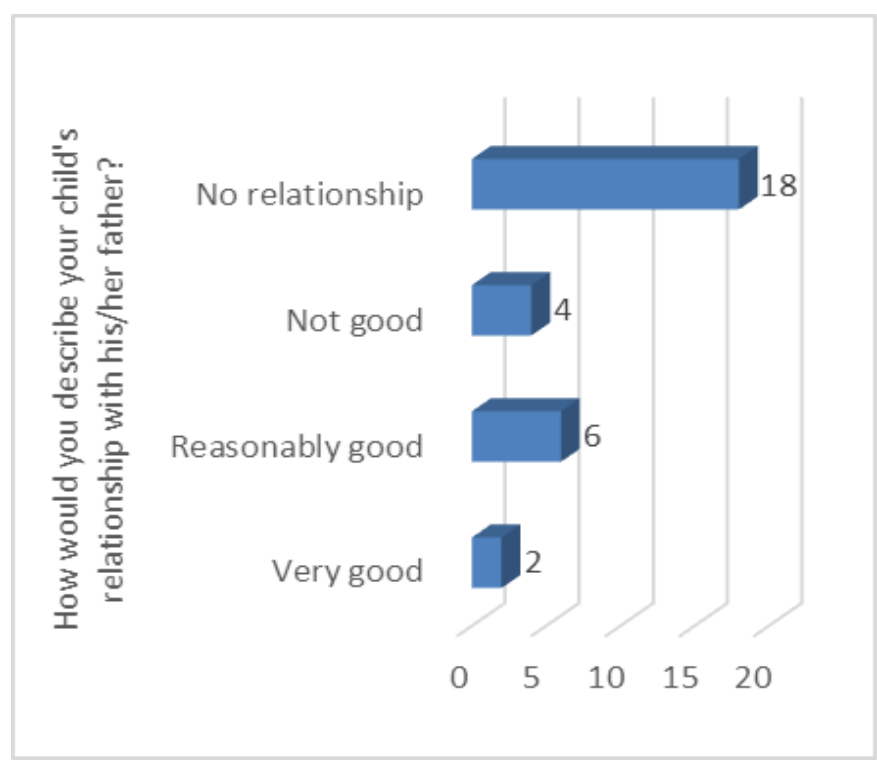

Figure 8. Mothers' perceptions of child's relationship with father 


\section{Al Macrothink}

Interestingly, the data show that whilst many of the mothers indicated that they felt that their children missed their father and needed to spend more time with them, when asked if they felt that this feeling was reciprocal, only a few of the mothers (5 or 16.7 percent) responded positively. The majority of the respondents 25 or 83.3 percent could not positively state that the child's father wanted to spend time with the child. However, another factor that was considered important to the child's relationship with the father, was the quality of the relationship which the child's parents. Quality of relationship is important to child well-being. According to Barker and Chang (2013), it is the transactions, or the network of relationships, between the parents and the children, and also those between the children, that largely determine how the children develop.

Interestingly, only 8 or 26.7 percent of the mothers described their child's relationship with their father as very good or reasonably good with the large majority 22 or 73.3 percent stating that the relationship was either not good or there was no relationship.

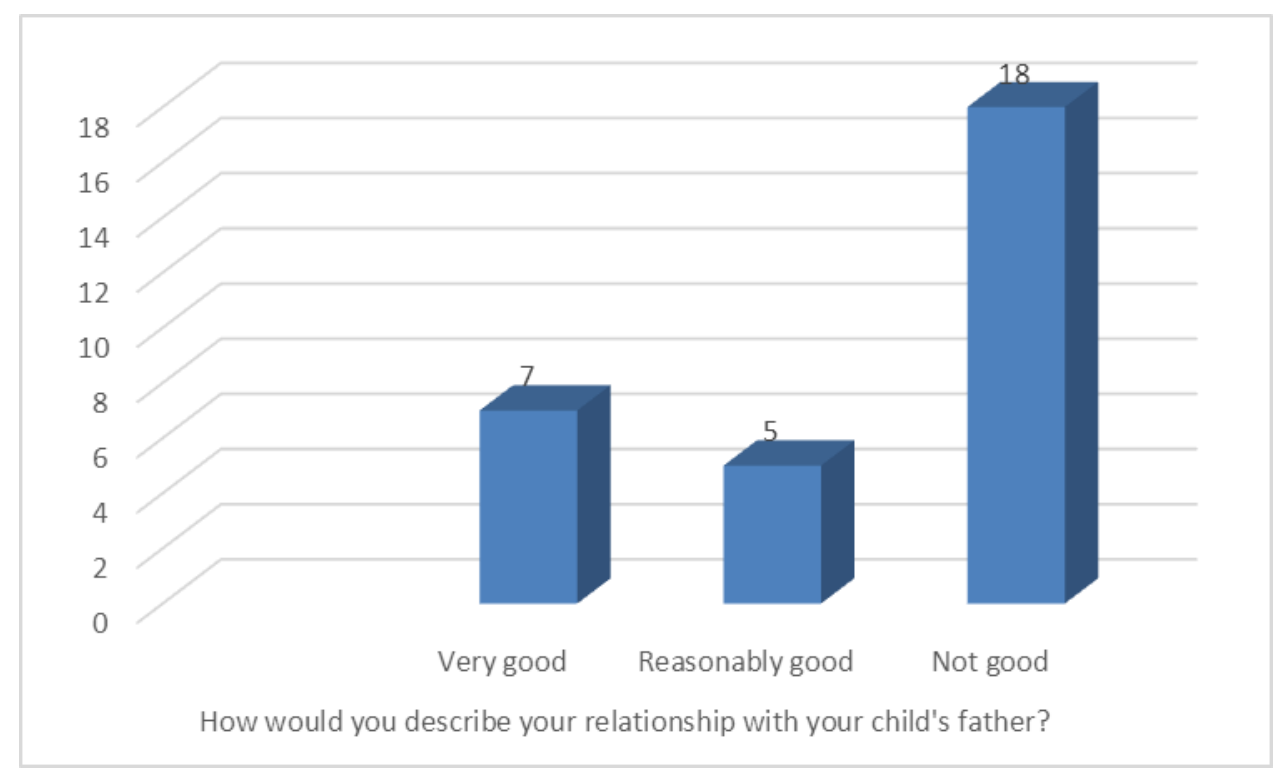

Figure 9. Mothers' perceptions on relationship with child-father

It has been stated by fathers that their relationships with their children have been impeded by the quality of their relationships with the mothers of their children. (Henry, 2015) This study found out that just about 1 in every 5 of the respondents ( 7 or 23 percent), had a reasonably good relationship with the father of their child, whilst about 4 in every 5 of the respondents (23 or 77 percent), indicated that their relationship was either not good or there was no relationship, supporting earlier reports from fathers. Obviously if the mothers do not have a good relationship fathers, then it is more than likely that the children who live with their mothers will also not have a good relationship with their fathers. Clearly, this study underscores the importance of financial support to child and family well-being but reiterates that ultimately relationships will determine the social and emotional well being of the child. However, relationship seems to be linked in part to timely payment of child support, as well 
as the quality of relationships between the parents. This was evident following the data which show that fathers who paid on time consistently tended to have better relationships with children as well as their child's mothers. The dichotomy was observed where mothers expressed the need for the child to have a relationship with their father but offered no suggestions on how such a relationship could be managed in the best interest of the child even when fathers do not pay or have other relationships.

\section{Conclusions and Recommendations}

There are a couple of fundamental issues which will have to be addressed in order to improve the economic and emotional child well being when one examines child maintenance from the perspective of mothers. Undoubtedly emotional well being is tied to financial security, and if the child is in a home where the mother is constantly concerned about finances and is angry with a father who is not meeting his financial commitments through the Court or otherwise, then the child's well being will be affected.

Table 2. Data showing Guyana's Population with focus on child population

\begin{tabular}{lccc}
\hline Indicator & Total & Male & Female \\
\hline Total Population (thousands) & 751 & 376 & 375 \\
Population (thousands) under 15 & 267 & 135 & 132 \\
Population (thousands) under 18 & 267 & & \\
Population under 5 (\%) & 10.4 & 9.4 & 9.9 \\
Population annual growth rate (\%) & $0.3 \%$ & $2.7 \%$ & $1.1 \%$ \\
Population that is urbanized, \% & $28.5 \%$ & $48.3 \%$ & $51.7 \%$ \\
Life expectancy at birth (years) & 68.8 & 65.7 & 72.1 \\
\hline
\end{tabular}

Data extracted from UNICEF 2014 Childcare and Mapping Assessment Report/2006 HIES Report

Further, there is a direct correlation between child support ad child poverty. Drawing upon the UNICEF 2014 unpublished report, written by Henry, children not only make up a significant portion of Guyana's population, but are also a significant portion of Guyana's poor. This is corroborated by the 2006 HIES, which states that half of all children aged 16 and below are poor (47.5\%). About 86 percent of population, living in hinterland regions, live in extreme poverty and child poverty as consequence of the poverty rates is also high. The 2011 Guyana Poverty Reduction Strategy Paper (PRSP) also identified the need for a strategy to rapidly tackle child poverty in Guyana and an even deeper analysis into generational poverty. The current system places the burden of care on parents but when one parent is no longer a part of the system that cares, the option for the mothers is to seek legal redress through child support. In seeking support, the burden of proof rests with the mother, to file the claim, identify the father so that the summons for payment can be served. Fathers 
tend to feel that women summon them out of vindictiveness after they would have moved on or ended their relationships.

However, whilst the burden is to provide is still seen as a male role, it must be also noted that some fathers due to their financial situation are just unable to be the provider at the time since they too may be living in poverty, due to unemployment or a range of other circumstances that have not been examined. Resultantly, the only other social security measure to which mothers may have recourse, is to seek public assistance. Public assistance is a social security option which is used to support persons who demonstrate the need after passing the means test. In seeking public assistance however, mothers have to prove that they do not know where fathers are located and that they get no support for the child. Mothers also have to meet other criteria so that even where they may be employed for a low salary, they may not be eligible for assistance. Thus what currently exists is a social security system that does not fully assess the financial situation of the mother seeking support.

Currently there is no system nor policy in place to determine alternatives if fathers cannot pay which would allow for financial support for the child and family well-being. As it is currently, mothers and children are solely faced with the economic stress when fathers do not or cannot pay. The economic distress placed upon both mothers and children may be additional factors which contribute to both women and children being more affected by poverty in Guyana and to other dysfunctional behaviours such as underperformance in schools, school dropouts, child crime, teenaged pregnancy and a range of other related issues.

As long as the environment is safe and conducive to their well-being, children need to be in positive relationships with both parents. Very often fathers do not benefit from these relationships based on the quality of the relationships with the mother of the child. Whilst mothers and fathers both indicate that there is the need for fathers to have better relationships, neither have not offered suggestions as to how these can work in the best interest of the child. Earlier self report studies from fathers in Guyana (Henry,2015) have shown that fathers were willing to support their children and be a part of the child's life however, many of these fathers are themselves low-income and are barely eking out a livelihood for themselves and can ill afford to maintain an active role in the life of their child especially when they have formed new unions with additional children. Child poverty is doubled when fathers do not or cannot pay and mothers are unemployed and are in other non-supportive relationships. The formal system, both the Court and arm of government social protection system responsible for child care needs to develop a policy particularly for parents who will continue to be affected by the child support system if it is not fixed. This system must consider the father socio-economic status and a plan of support so that fathers can eventually undertake responsible child maintenance. Perceptions of bias towards mothers will be removed by a system that allows for parents, both mothers and fathers, to be involved in decisions pertinent to child support and child wellbeing.

\section{References}

Camfield, L. Streuli, N., \& Woodhead, M. (2009). What's the Use of 'Well-Being' in Contexts of Child Poverty Approaches to Research Monitoring and Children's Participation. The 
International Journal of Children' s Rights, 17(1), 1-45. http://dx.doi.org/10.1163/157181808 X357330

Guyana. (2011). Poverty Reduction Strategy Paper (PRSP).

Hart, J. (2004). Children's Participation in Humanitarian Action: Learning from Zones of Armed Conflict, Synthesis Report prepared for the Canadian International Development.

Henry, P. (2015). Child Maintenance, Father Child Relationship and Child wellbeing. Issues in Social Science, 3(2). http://dx.doi.org/10.5296/iss.v3i2.7693

Huang, C -C. (2009). Mothers' Reports of Nonresident Fathers' Involvement with Their Children: Revisiting the Relationship between Child Support Payment and Visitation Source. Family Relations, 58(1), 54-64. [Online] Available: http://www.jstor.org/stable/20456836

NA. (2003). Caribbean Families. International Encyclopedia of Marriage and Family. [Online] Available: http://www.encyclopedia.com/doc/1G2-3406900063.html

Pirog, M. A., \& Ziol-Guest, K. M. (2006). Child support enforcement: Programs and policies, impacts and questions. Journal of Policy Analysis and Management, 25(4), 943-990. http://dx.doi.org/10.1002/pam.20215

Republic of Guyana. (2009). Protection of Children Act.

Republic of Guyana. (2010). Poverty Reduction Strategy Paper 2011-2015.

Seegobin, W. (1999). Important considerations in counseling Asian Indians. In K. S. Ng. Alexandria (ed.), Counseling Asian Families from A Systems Perspective, American Counseling Association.

Sharpe, J. (1996). Mental health issues and family socialization in the caribbean. In J. L. Roopnarine, \& J. B. Greenwich (eds.), Caribbean Families: Diversity among Ethnic Groups.

Teitler, J. O. et al. (2004). Sources of Support, Child Care, and Hardship among Unwed Mothers, 1999-2001. Social Service Review, 78(1). http $/ /$ dx.doi.org/125-148.10.1086/380770

UNICEF. (2014). A Report on the key findings of the mapping and assessment of the Child Protection System in Guyana (unpublished report prepared by P. Henry).

Waller M., \& Plotnick, R. (2001). Effective Child Support Policy for Low-Income Families: Evidence from Street Level Research. Journal of Policy Analysis and Management, 20(1), 89-110. [Online] Available: http://www.jstor.org/stable/3325595 